Syntax Literate : Jurnal Ilmiah Indonesia p-ISSN: 2541-0849

e-ISSN : 2548-1398

Vol. 5 No. 4 April 2020

\title{
PENGARUH DISTRIBUSI TERHADAP KEPUASAN KONSUMEN PADA CV MAJA MENJANGAN KABUPATEN MAJALENGKA
}

\section{Tia Aprilia Susnita}

Sekolah Tinggi Ilmu Ekonomi (STIE) STMY Majalengka

Email: tiasusnita@gmail.com

\section{Abstract}

The purpose of this research is to gather information that will be used to analyze the effect of distribution on consumer satisfaction at CV Maja Menjangan, Majalengka Regency. And is expected can help companies solve problems faced in accordance with the topic taken by the author, by analyzing, especially information and data about the effect of distribution on customer satisfaction. The research method used in this research is descriptive and verification methods. The population of this research is the consumers of CV Maja Menjangan, Majalengka Regency whose exact numbers are unknown. Because the population is unknown, sampling is taken using the formula from Wibisono. Based on the calculation, the number of samples studied was 96 respondents. Techniques of data collection that author uses is: interviews, observation, questionnaires and literature studies. Techniques of data analysis used are correlation coefficient, regression, determination and hypothesis testing or t-test. From the results of this research can be concluded as follows: there is an influence between the distribution of customer satisfaction because tcount is greater than ttable (12.5798> 1.66123). The correlation value between distribution and constumer satisfaction at CV Maja Menjangan Majalengka Regency based on research data obtained was 0.7921 . The relationship between distribution variables and customer satisfaction on CV Maja Menjangan Majalengka Regency was included in the category of strong relationships. The contribution of distribution to consumer satisfaction is $62.74 \%$ or it can be said also, that the variance that occurs in the variable of customer satisfaction $(Y) 62.74 \%$ is determined by the variance that occurs in the distribution variable $(X)$. The remaining $37.26 \%$ is determined by factors outside this research. Then the Regression Equation is: $Y=5.12+0.74 X$. It means: $b$ is positive that is 5.12 means there is a positive effect of $X$ on $Y$. The regression coefficient of 0.74 states that each increase (because $b$ is marked +) 1 distribution units will increase customer satisfaction by 0.74 units.

Keywords : Distribution and costumer satisdication.

\section{Abstrak}

Maksud dari penelitian ini adalah untuk mengumpulkan informasi yang akan digunakan untuk menganalisis pengaruh distribusi terhadap kepuasan konsumen pada CV Maja Menjangan Kabupaten Majalengka. Dan diharapkan dapat membantu perusahaan dalam menyelesaikan masalah yang dihadapi sesuai dengan topik yang diambil penulis, dengan cara menganalisis, khususnya informasi dan 
data mengenai pengaruh distribusi terhadap kepuasan konsumen. Metode penelitian yang digunakan dalam penelitian ini metode deskriptif dan verivikatif. Adapun yang menjadi populasi penelitian ini adalah konsumen CV Maja Menjangan Kabupaten Majalengka yang tidak diketahui jumlahnya secara pasti. Oleh karena populasi tidak diketahui maka pengambilan sampel dilakukan dengan menggunakan rumus dari Wibisono. Berdasarkan hasil perhitungan maka jumlah sampel yang diteliti yaitu sebanyak 96 responden. Teknik pengumpulan data yang penulis gunakan adalah: wawancara, observasi, angket dan studi literature. Teknik analisis data yang digunakan yaitu koefisien korelasi, regresi, determinasi dan uji hipotesis atau uji t. Dari hasil penelitian dapat disimpulkan sebagai berikut : terdapat pengaruh antara distribusi terhadap kepuasan konsumen karena $t_{\text {hitung }}$ lebih besar dari $t_{\text {tabel }}(12,5798>1.66123)$. Nilai korelasi antara distribusi dengan kepuasan konsumen pada CV Maja Menjangan Kabupaten Majalengka berdasarkan data penelitian yang diperoleh adalah sebesar 0,7921 Maka hubungan variabel distribusi dengan kepuasan konsumen pada CV Maja Menjangan Kabupaten Majalengka masuk dalam kategori hubungan yang kuat. Kontribusi distribusi dengan kepuasan konsumen adalah sebesar 62,74\% atau dapat dikatakan pula, bahwa varians yang terjadi pada variabel kepuasan konsumen (Y) 62,74\% ditentukan oleh varians yang terjadi pada variabel distribusi (X). Sisanya, sebesar $37,26 \%$ ditentukan oleh faktor-faktor diluar penelitian ini. Maka Persamaan Regresinya adalah : $\mathrm{Y}=5,12+0,74 \mathrm{X}$. Artinya : b bersifat positif yaitu 5,12 artinya terdapat pengaruh positif $\mathrm{X}$ terhadap $\mathrm{Y}$. Koefisien regresi sebesar 0,74 menyatakan bahwa setiap peningkatan (karena b bertanda +) 1 satuan distribusi akan meningkatkan kepuasan konsumen sebesar 0,74 satuan.

Kata kunci : Distribusi dan kepuasan konsumen

\section{Pendahuluan}

Kepuasan konsumen saat pembelian merupakan suatu kepuasan atas pemilihan dari tindakan dua atau lebih pilihan alternatif (Sumarwan, 2011). Konsumen ialah sumber penghasilan bagi perusahaan dan aspek terpenting yang harus diperhatikan khusus, oleh karenanya harapan dan kebutuhan konsumen harus dapat dipenuhi oleh perusahaan (Kamaludin, 2019). Setiap orang pasti pernah mempertimbangkan sesuatu hal sebelum melakukan pembelian. Apakah produk yang akan dibeli sudah sesuai dengan kebutuhannya atau keinginannya. Kemudian produk yang akan dibeli tersebut apakah sudah sesuai dengan kondisi dirinya, seperti harga yang sesuai untuk mendapatkan suatu produk yang diinginkan. Tingkat keterlibatan konsumen dalam suatu pembelian juga bisa dipengaruhi oleh stimulus (rangsangan) yang termasuk dalam bauran pemasaran (marketing mix). Banyak faktor yang dapat mempengaruhi kepuasan konsumen dalam pembelian seperti produk, harga, promosi dan distribusi atau yang dikenal dengan bauran pemasaran. Bauran pemasaran adalah proses penggabungan dalam strategi pemasaran yang disesuaikan dengan kondisi masing-masing perusahaan yang terstandarisasi dengan produk, harga yang rendah, dan saluran distribusi (Kotler \& Keller, 2009). 
Dengan pengelolalan distribusi yang baik, profesional diharapkan akan menciptakan suasana menyenangkan bagi konsumen, dan itu berarti konsumen akan merasa puas. Dengan banyaknya persaingan, pengusaha yang bergerak di pasar tradisional harus proaktif mendatangi pelanggan/konsumen untuk menawarkan produkproduk dengan berbagai kemudahan dan pelayanan agar pelanggan merasa puas. Tidak hanya sekedar puas, namun pelanggan inti harus dapat dipertahankan serta dapat merebut pelanggan must-have menjadi pelanggan inti (Gordman \& Brott, 2007).

Menyadari pentingnya kegiatan distribusi bagi kelanjutan usaha suatu perusahaan, maka kegiatan ini harus dilakukan agar dapat memuaskan dan tentunya mempertahankan pelanggan. Menurut (Carthy, M., n.d.) pelanggan bisnis pada umumnya mencoba untuk mempertahankan sediaan dalam jumlah yang cukup, untuk mencegah terjadinya kekurangan sediaan agar tidak kehilangan penjualan mereka jika produk-produk yang dibutuhkan konsumen tidak tersedia. Untuk itu, pemasok harus mampu mengirimkan pesanan tepat waktu (just in time delivery).

Dalam keadaan seperti ini, distribusi fisik (pengangkutan dan penyimpanan barang "logistik") harus mendapat perhatian khusus dari perusahaan. Pelanggan tidak peduli bagaimana produk diangkut atau disimpan, atau terhadap apa yang harus dilakukan oleh anggota saluran untuk menyediakannya. Pelanggan hanya berpikir dari segi tingkat layanan pelanggan, seberapa cepat dan handal suatu perusahaan dapat menyampaikan yang mereka inginkan. Jika perusahaan kurang cepat dan handal dalam menyediakan permintaan pelanggan, maka pelanggan yang kurang loyal akan segera berpindah kepada penjual lainnya.

\section{Metode Penelitian}

Jenis metode penelitian yang digunakan yaitu metode deskriptif dan verifikatif. Metode deskriptif adalah suatu metode penelitian yang bertujuan untuk menggambarkan, menjelaskan keadaan pada CV Maja Menjangan Kabupaten Majalengka berdasarkan data dan fakta yang dikumpulkan kemudian disusun secara sistematis yang selanjutnya dianalisis untuk mendapatkan kesimpulan. Sedangkan metode verifikatif adalah metode yang digunakan untuk menguji hipotesis dengan menggunakan statistik.

Subyek dalam penelitian ini adalah seluruh konsumen CV Maja Menjangan yang tidak dapat diketahui jumlahnya secara pasti sehinngga pada penelitian ini populasi yang diambil berukuran besar dan jumlahnya tidak diketahui secara pasti. Dalam penentuan sampel jika populasinya besar dan jumlahnya tidak diketahui maka menurut (Iswayanti \& Dwiyanto, 2010) digunakan rumus :

$$
n=\frac{Z^{2}}{4(M o e)^{2}}
$$

Sehingga didapatlah sampel sebanyak 96 orang, Teknik pengambilan sampling yang digunakan adalah non probability sampling, yaitu teknik pengambilan sampel yang tidak memberi peluang/kesempatan sama bagi setiap unsur atau anggota populasi untuk dipilih menjadi sampel. Metode pengambilan sampelnya menggunakan sampling 
aksidental, teknik penentuan sampel berdasarkan kebetulan. Teknik pengumpulan data menggunakan instrumen penelitian berupa angket, dan terlebih dahulu dilakukan uji instrumen dengan uji valditas dan uji reliabilitas.

\section{Hasil dan Pembahasan}

\section{A. Hasil Penelitian}

Berikut adalah hasil pengujian korelasi,regresi dan uji hipotesis dengan menggunakan software SPSS versi 20.

\section{1) Uji koefisien Korelasi}

\begin{tabular}{|c|c|c|c|}
\hline \multicolumn{4}{|c|}{ Correlations } \\
\hline & & Distribusi & $\begin{array}{l}\text { Kepuasan } \\
\text { Konsumen }\end{array}$ \\
\hline \multirow{3}{*}{ Distribusi } & $\begin{array}{l}\text { Pearson } \\
\text { Correlation }\end{array}$ & 1 &, $792^{* *}$ \\
\hline & Sig. (2-tailed) & & ,000 \\
\hline & $\mathrm{N}$ & 96 & 96 \\
\hline \multirow{3}{*}{$\begin{array}{l}\text { Kepuasan } \\
\text { Konsumen }\end{array}$} & $\begin{array}{l}\text { Pearson } \\
\text { Correlation }\end{array}$ &, $792^{* *}$ & 1 \\
\hline & Sig. (2-tailed) & ,000 & \\
\hline & $\mathrm{N}$ & 96 & 96 \\
\hline
\end{tabular}

Hasil perhitungan nilai korelasi antara distribusi dengan kepuasan konsumen pada CV Maja Menjangan Kabupaten Majalengka berdasarkan data penelitian yang diperoleh adalah sebesar 0,7921 nilai ini menunjukkan kekuatan hubungan variabel distribusi dengan kepuasan konsumen pada CV Maja Menjangan Kabupaten Majalengka. Hubungan variabel distribusi dengan kepuasan konsumen pada CV Maja Menjangan Kabupaten Majalengka masuk dalam kategori hubungan yang kuat.

\section{2) Uji koefisien Determinasi}

Model Summary

\begin{tabular}{lrrrr}
\hline $\begin{array}{l}\text { Mod } \\
\text { el }\end{array}$ & R & R Square & $\begin{array}{c}\text { Adjusted R } \\
\text { Square }\end{array}$ & $\begin{array}{l}\text { Std. Error of } \\
\text { the Estimate }\end{array}$ \\
\hline 1 &, $792^{\mathrm{a}}$ &, 627 &, 623 & 1,64597 \\
\hline
\end{tabular}

a. Predictors: (Constant), Distribusi

Dengan demikian, maka kontribusi distribusi dengan kepuasan konsumen adalah sebesar $62,74 \%$ atau dapat dikatakan pula, bahwa varians yang terjadi pada variabel kepuasan konsumen (Y) 62,74\% ditentukan oleh varians yang terjadi pada variabel distribusi (X). Sisanya, sebesar 37,26\% ditentukan oleh faktor-faktor di luar penelitian ini. 
3) Uji Koefisien Regresi

\section{Coefficients $^{\mathrm{a}}$}

\begin{tabular}{llrrrrr}
\hline Model & \multicolumn{2}{c}{$\begin{array}{l}\text { Unstandardized } \\
\text { Coefficients }\end{array}$} & \multicolumn{2}{c}{$\begin{array}{c}\text { Standardized } \\
\text { Coefficients }\end{array}$} & & \multirow{2}{*}{ Sig. } \\
\cline { 2 - 6 } & \multicolumn{2}{c}{ B } & Std. Error & Beta & & \\
\hline \multirow{2}{*}{1} & (Constant) & 5,121 & 1,138 & & 4,500 &, 000 \\
& Distribusi &, 736 &, 059 &, 792 & 12,580 &, 000 \\
\hline
\end{tabular}

a. Dependent Variable: Kepuasan Konsumen

Maka Persamaan Regresinya adalah : $\mathrm{Y}=5,12+0,74 \mathrm{X}$

Artinya :

1. b bersifat positif yaitu 5,12 artinya terdapat pengaruh positif X terhadap Y.

2. Konstanta sebesar 5,12 menyatakan bahwa jika distribusi tidak dipertimbangkan $(\mathrm{X}=0)$, maka kepuasan konsumen adalah sebesar 5,12 satuan.

3. Koefisien regresi sebesar 0,74 menyatakan bahwa setiap peningkatan (karena b bertanda +) 1 satuan distribusi akan meningkatkan kepuasan konsumen sebesar 0,74 satuan.

4) Uji Hipotesis

Coefficients $^{\mathrm{a}}$

\begin{tabular}{|c|c|c|c|c|c|}
\hline \multirow[t]{2}{*}{ Model } & \multicolumn{2}{|c|}{$\begin{array}{c}\text { Unstandardized } \\
\text { Coefficients }\end{array}$} & \multirow{2}{*}{$\begin{array}{c}\begin{array}{c}\text { Standardized } \\
\text { Coefficients }\end{array} \\
\text { Beta }\end{array}$} & \multirow[t]{2}{*}{$\mathrm{t}$} & \multirow[t]{2}{*}{ Sig. } \\
\hline & B & $\begin{array}{l}\text { Std. } \\
\text { Error }\end{array}$ & & & \\
\hline (Constant) & 5,121 & 1,138 & & 4,500 &, 000 \\
\hline Distribusi & ,736 & ,059 & ,792 & 12,580 & ,000 \\
\hline
\end{tabular}

a. Dependent Variable: Kepuasan Konsumen

Sedangkan pada tingkat kesalahan $\alpha=0.05$ dan dk sebesar $94(\mathrm{n}-2=$ 96-2), didapat $t_{\text {tabel }}$ 1.66123. Berdasarkan perhitungan tersebut dapat diketahui bahwa $t_{\text {hitung }}$ lebih besar dari $\mathrm{t}_{\text {tabel }}(12,5798>1.66123)$, hal ini dapat diartikan distribusi berpengaruh terhadap kepuasan konsumen pada CV Maja Menjangan Kabupaten Majalengka.

\section{B. Pembahasan}

\section{Pengaruh Distribusi terhadap kepuasan konsumen}

Hasil penelitian menunjukkan bahwa distribusi berpengaruh positif dan signifikan terhadap Kepuasan pelanggan. Hasil pengujian secara statistik. Distribusi merupakan suatu sistem pemasaran yang sangat penting dalam upaya menyampaikan produk pada target pasar pada saat yang tepat. Bila distribusi yang dilaksanakan sesuai dengan sasaran yang dituju atau yang direncanakan oleh perusahaan tersebut maka perusahaan akan mengalami keuntungan, jadi hubungan distribusi dengan kepuasan konsumen saling terkait satu dengan yang lain. saluran 
distribusi mempunyai tugas menyampaikan produk ataupun jasa yang diproduksi oleh perusahaan atau produsen kepada para konsumen. Perusahaan juga menyediakan saluran distribusi agar untuk memuaskan pelanggan. Saluran distribusi diharapkan memberikan kemudahan untuk pelanggan jika rumah jauh dari perusahaan dengan adanya saluran distribusi barang tersebut bisa langsung di antarkan ke tempat pelanggan atau bisa di katakan service dari perusahaan. Agar pelanggan merasa nyaman dengan fasilitas yang di berikan oleh perusahaan, agar diharapkan dapat memberikan pengaruh positifterhadap meningkatnya penjualan tersebut diharapkan dapat memperoleh pelanggan baru dan mempertahankan pelanggan lama.

\section{Kesimpulan}

Distribusi pada CV Maja Menjangan Kabupaten Majalengka sudah berjalan dengan baik, dapat diketahui persentase skor akumulasi tanggapan responden sebesar 76,96\% yang masuk dalam kategori baik.

Kepuasan konsumen pada CV Maja Menjangan Kabupaten Majalengka dalam tingkatan baik, dapat diketahui persentase skor akumulasi tanggapan responden sebesar $77,13 \%$ termasuk dalam kategori baik.

Terdapat pengaruh antara distribusi terhadap kepuasan konsumen karena $\mathrm{t}_{\text {hitung }}$ lebih besar dari $\mathrm{t}_{\text {tabel }}(12,5798>1.66123)$. Nilai korelasi antara distribusi dengan kepuasan konsumen pada CV Maja Menjangan Kabupaten Majalengka berdasarkan data penelitian yang diperoleh adalah sebesar 0,7921 Maka hubungan variabel distribusi dengan kepuasan konsumen pada CV Maja Menjangan Kabupaten Majalengka masuk dalam kategori hubungan yang kuat. Kontribusi distribusi dengan kepuasan konsumen adalah sebesar $62,74 \%$ atau dapat dikatakan pula, bahwa varians yang terjadi pada variabel keputusan pembelian (Y) 62,74\% ditentukan oleh varians yang terjadi pada variabel distribusi (X). Sisanya, sebesar 37,26 \% ditentukan oleh faktor-faktor diluar penelitian ini. Maka Persamaan Regresinya adalah : Y = 5,12 +0,74 X. Artinya : b bersifat positif yaitu 5,12 artinya terdapat pengaruh positif $\mathrm{X}$ terhadap Y. Koefisien regresi sebesar 0,74 menyatakan bahwa setiap peningkatan (karena b bertanda +) 1 satuan distribusi akan meningkatkan kepuasan konsumen sebesar 0,74 satuan. 
Tia Aprilia Susnita

\section{BIBLIOGRAFI}

Carthy, M., \& P. (n.d.). Intisari Pemasaran, Sebuah Rancangan Manajerial Global. (Jilid I). Jakarta: Jakarta: Bina Aksara.

Gordman, R., \& Brott, A. (2007). The Must Have Customer: 7 Taktik Jitu Merebut Hati Pelanggan Idaman Anda. Gramedia, Jakarta.

Iswayanti, I. P., \& Dwiyanto, B. M. (2010). Analisis Pengaruh Kualitas Produk, Kualitas Layanan, Harga, dan Tempat Terhadap Keputusan Pembelian (Studi pada rumah makan "Soto Angkring Mas Boed” di Semarang). Universitas Diponegoro.

Kamaludin, A. (2019). Hubungan Kualitas Pelayanan Terhadap Kepuasan Konsumen Pada Apotik Puji Lestari Majalengka. Syntax Literate; Jurnal Ilmiah Indonesia, 4(12), 47-55.

Kotler, P., \& Keller, K. L. (2009). Manajemen pemasaran. edisi.

Sumarwan, U. (2011). Perilaku konsumen: Teori dan penerapannya dalam pemasaran. Bogor: Ghalia Indonesia. 